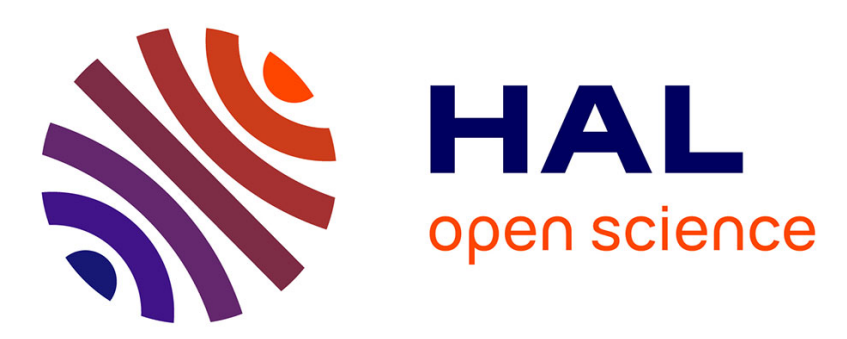

\title{
An optical system for monitoring seabed evolutions at a coastal structure
}

Hervé Michallet, Jean-Paul Barbier-Neyret, Mathieu Mory, I. Piedra-Cueva

\section{To cite this version:}

Hervé Michallet, Jean-Paul Barbier-Neyret, Mathieu Mory, I. Piedra-Cueva. An optical system for monitoring seabed evolutions at a coastal structure. ASCE Fifth International Conference on Coastal Dynamics, Apr 2005, Barcelona, Spain. 10.1061/40855(214)66 . hal-00260415

\section{HAL Id: hal-00260415 https://hal.science/hal-00260415}

Submitted on 10 Feb 2020

HAL is a multi-disciplinary open access archive for the deposit and dissemination of scientific research documents, whether they are published or not. The documents may come from teaching and research institutions in France or abroad, or from public or private research centers.
L'archive ouverte pluridisciplinaire HAL, est destinée au dépôt et à la diffusion de documents scientifiques de niveau recherche, publiés ou non, émanant des établissements d'enseignement et de recherche français ou étrangers, des laboratoires publics ou privés.

\section{(c)(1)}

Distributed under a Creative Commons Attribution| 4.0 International License 


\title{
AN OPTICAL SYSTEM FOR MONITORING SEABED EVOLUTIONS AT A COASTAL STRUCTURE
}

\author{
H. Michallet ${ }^{1}$, J.-P. Barbier-Neyret ${ }^{2}$, M. Mory ${ }^{3}$, I. Piedra-Cueva ${ }^{4}$ \\ ${ }^{1}$ Laboratoire des Ecoulements Géophysiques et Industriels (LEGI), CNRS-INPG-UJF, BP53, 38041 \\ Grenoble cedex 9, France. herve.michallet@ @mg.inpg.fr. \\ ${ }^{2}$ LEGI. jean-paul.barbier-neyret@hmg.inpg.fr. \\ ${ }^{3}$ ENSGTI (UPPA), BP7511, 64075 Pau cedex. France, mathieu.mory@univ-pau.fr. \\ ${ }^{4}$ IMFIA, Facultad de Ingeniería, Julio Herrera y Reissig 565, 11300 Montevideo, Uruguay. \\ ismaelp@fing.edu.uy.
}

\begin{abstract}
An optical system has been designed for measuring the bed level, sand grain motions inside the soil and the presence of suspension at the toe of a coastal structure exposed to breaking waves. These measurements were conducted in the framework of the LIMAS project. We show that the soil is not strictly stable even at great depths (about $1 \mathrm{~m}$ ). The generation of pressure differences in the soil is the main mechanism for this instability at the wall facing the waves. At the corner of the structure, the shear induced by large longitudinal velocities enhances the sediment transport and scour.
\end{abstract}

\section{INTRODUCTION}

The sediment transport at the toe of a coastal structure exposed to breaking waves is generally very difficult to observe. Due to suspension and aeration, it is often impossible to visualize the bed level. An optical system has been designed to estimate the behaviour of the soil under breaking wave activity.

Conductivity probes, as described by Babu et al. (2003), may be used to follow bed evolution and scour in laboratory experiments with fresh water. However, it appears that the discrepancies between conductivities in the saturated soil and in the water column are not so large in sea-water and this may complicate the interpretation of the measurements (Cassen et al., 2004).

Optical backscatter systems (OBS) are often used to estimate sediment concentrations (e.g. Conley and Beach, 2003). Other studies have also used this technique to estimate the bed level evolution (e.g. Lee et al., 2004). The physical principle of our system is basically the same. Instead of trying to carefully estimate the sediment concentration in the water column, we focussed in the interpretation 
of bed level evolution and also the response inside the soil. We show in the present paper that we may qualify the soil stability by sampling at high frequencies $(100 \mathrm{~Hz})$.

This work was performed in the framework of field measurements of the LIMAS project (Bonjean et al. 2004; Mory et al., 2005; Piedra-Cueva et al. 2005). The main goal of these experiments was to determine the occurrence of liquefaction through pressure measurements at various depths. A last world war bunker exposed to wave activity at high tide was instrumented. Two different configurations have been considered: the instruments located at the middle of the bunker's front facing the waves and the instruments located at the bunker's corner where significant scour has been observed (the latter configuration is shown in Fig. 1). Special attention has been paid to the estimation of the bed level for interpreting the pressure variations. The aim of the present paper is to describe the designed optical system and soil response in more detail. Moreover, the comparison between measurements in the two configurations is presented.

The paper is organized in the following manner. We first describe the experimental configuration and the deployed instruments with special emphasis on the optical system. The bed evolution is discussed for two configurations (bunker's front and corner) and a range of timescales, from small (wave) to large (tide). A general view of soil stability at the toe of a coastal structure exposed to breaking waves is thus given.

\section{CONFIGURATION OF THE EXPERIMENTS}

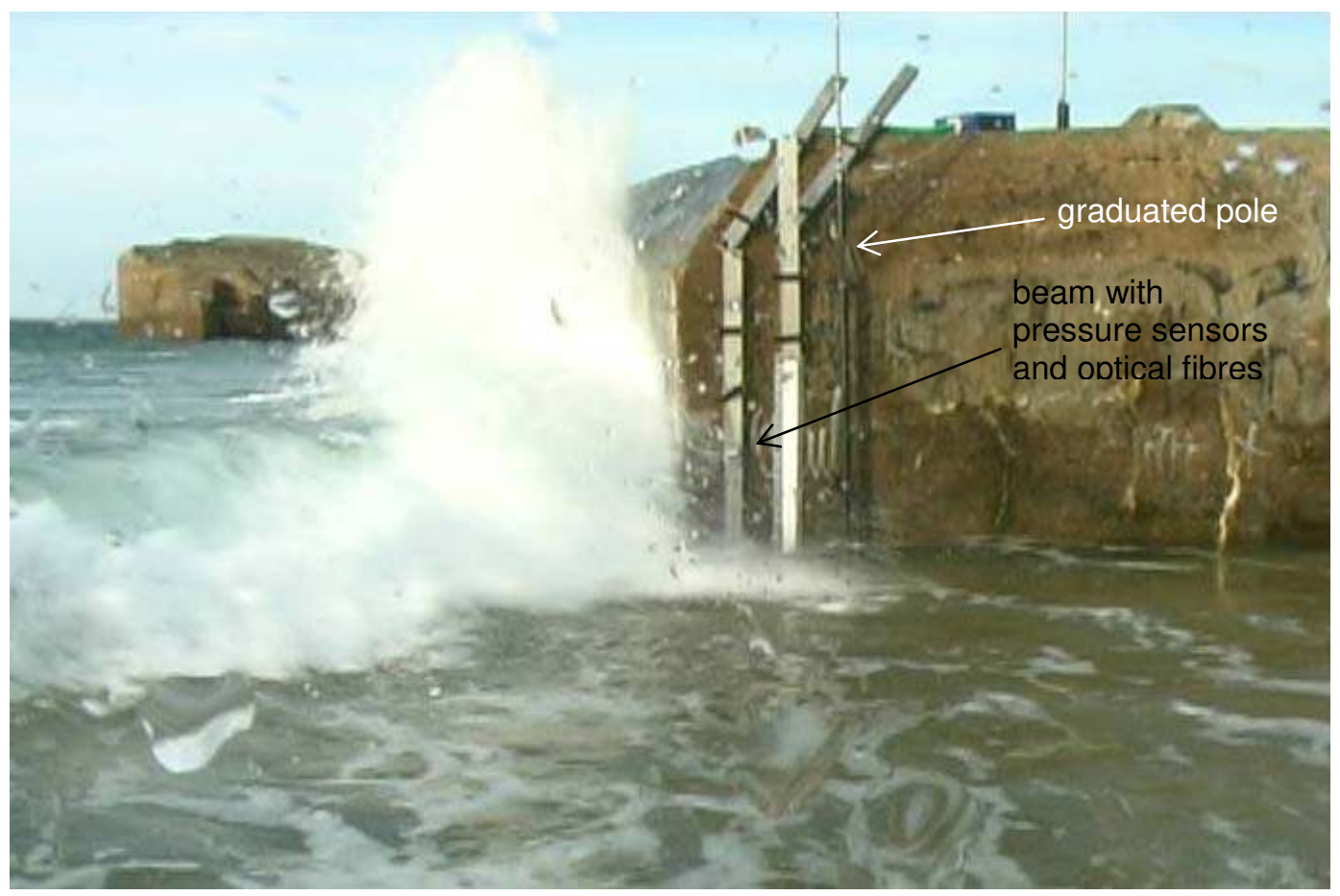

Fig. 1. Instrumented bunker (corner configuration). 


\section{Instruments considered}

The experimental set-up has been described in Mory et al. (2005). Five pressure and eight optical sensors are placed inside a steel beam, the tips of the sensors facing outward. The five pressure sensors are spaced every $30 \mathrm{~cm}$, five optical sensors at the same level and three other placed inbetween the four upper pressure sensors. The steel beam is rigidly fixed to the bunker in order to (i) avoid any displacement of the beam relatively to the structure and (ii) have sensors in the water column as well as deep into the soil.

A graduated pole was also used to estimate the bed level during high tide (see Fig. 1). The pole would stand on the sand bed and fall down when erosion occurred. The pole could be lifted up and placed on the new bed level if accretion occurred. This system is very robust and relatively accurate with a precision of the order of $1 \mathrm{~cm}$. Its main drawback is poor time resolution, which depends on the action of the operator.

Underwater video recordings were conducted under moderate wave activity. This was an additional check of the bed level estimate and suspension activity.

\section{Principle of the optical system}

A sensor is made up of two optical fibres set in parallel inside the steel beam, the fibre tips facing outward. One of the fibres is the emitter of light, the other one is the receptor. It is possible to determine what is in front of the sensor based on the reflected light level. In order to remove surrounding light effects, the incoming light is switched alternatively on and off (at $500 \mathrm{~Hz}$ ). The level of backscattered light when the emission is off is suppressed from the measure when the emission is on. Fibre tips are $0.8 \mathrm{~mm}$ in diameter and $0.5 \mathrm{~mm}$ apart in order to reduce the measurement volume to a few $\mathrm{mm}^{3}$. In order to detect rapid variations of the soil properties as liquefaction events, the sampling frequency was set to $100 \mathrm{~Hz}$.

\section{Calibration}

The response to a calibrating test is shown in Fig.2. The beam was laid horizontally under water, sensors facing upward. Sand is poured on the sensors at time $t=9 \mathrm{~s}$. The response of the system is a rapid increase. The beam is then turned upside down to let the sand fall at $t=45 \mathrm{~s}$. We note that it takes a few seconds for the output to stabilize at the minimum level corresponding to clear water. The beam is then turned aside. At $t=120 \mathrm{~s}$, a cloud of sand is dropped in front of the sensor. The threshold level has been set to $2.5 \mathrm{~V}$.

Since the sediment colour and size vary widely in our field conditions (see for instance the pictures in Fig. 3), any calibration to precisely infer sediment concentration is hopeless. We therefore do not intend to translate output voltages into concentrations or soil compaction. We nevertheless deduce the following information from the measurements: (i) whether the sensor is in the soil; (ii) whether there is grain mobility in the soil; (iii) whether there is sediment suspension in the water column. The determination of these three aspects is justified in the next section. 


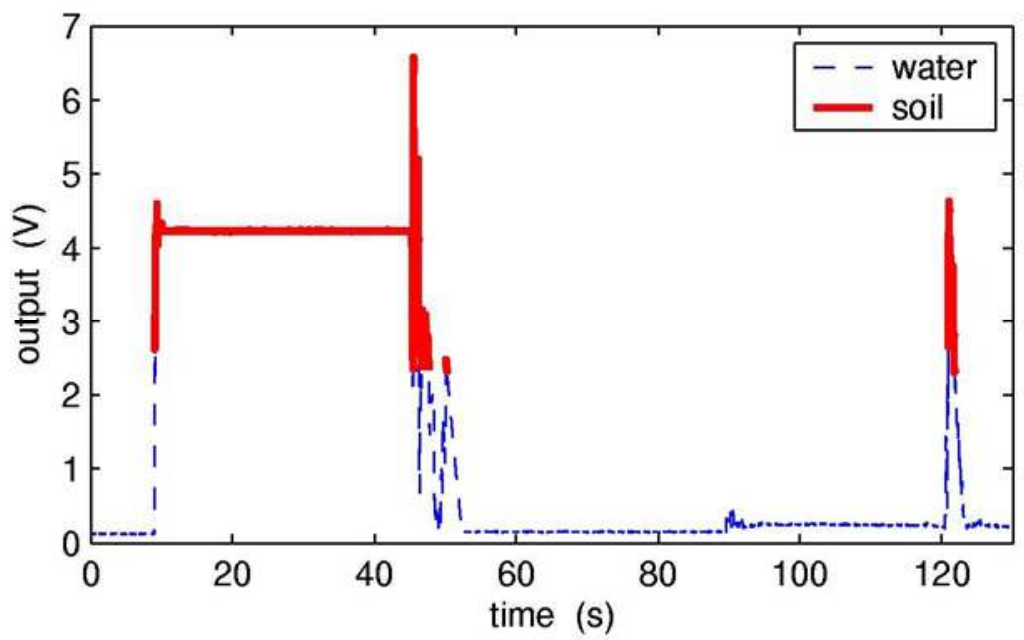

Fig. 2. Typical response of an optical sensor to a calibrating test (see text).

\section{OBSERVATIONS AND MEASUREMENTS}

\section{Sand motions at the time scale of the waves}

On September 29, the wave climate was calm enough to make videos of rather good quality. Video frames of this experiment are shown in Fig. 3. In that sequence, the beam is at the bunker's corner and only P1 (on the left of the beam) and o1 (on the right) are in the water column. The next sensors $\mathrm{P} 2$ and $\mathrm{o} 1-2$ are $20 \mathrm{~cm}$ and $5 \mathrm{~cm}$ below the soil/water interface respectively. The corresponding times series of pressure and optical outputs are shown in Fig. 4a and b. It is clear from these videos that below the wave troughs there is a strong offshore flow and shear that produces sediment transport (three top pictures in Fig. 3). Large sand grain motions are recorded at the optical sensor located 5 $\mathrm{cm}$ below the soil/water interface (sensor o1-2 in Fig. 4b). As the wave crest approaches, a vortex is generated at the bunker's corner and a large amount of sediment is put into suspension ( $\mathrm{t}=2.6 \mathrm{~s})$ reaching the area in front of the upper optical sensor (o1 in Fig. $4 \mathrm{~b}$ at $\mathrm{t}=2.8$ to $5.4 \mathrm{~s}$ ). Again, shear produces significant motion of the upper part of the soil around $t=10 \mathrm{~s}$. From the three last pictures in Fig. 3 we note that the sediment concentration can vary very rapidly and that the optical sensor response frequency (see Fig. $4 \mathrm{~b}$ ) is good.

If we now look at the response of an optical sensor located deeper into the soil (o2-3 in Fig. $4 \mathrm{~d}$ is located $35 \mathrm{~cm}$ below the soil/water interface), we observe smaller but significant variations that are in phase with the pressure differences shown in Fig. 4c (o2-3 is located in between P2 and P3). This is a general feature of the field campaign measurements. Optical outputs recorded small variations deep into the soil, which are in phase with the pressure differences.

The variations in output voltage are not directly proportional to sand grain displacements. Large sand grain motions may induce a small response of the system if there is a light change in sand grain colour, size and density. Besides, a large variation of the output voltage may be due to a small displacement of an air bubble trapped into the soil. Nevertheless, since all recorded motions are in phase with large variations of pressure differences, we are confident that the system is well designed for estimating soil stability at a coastal structure. 


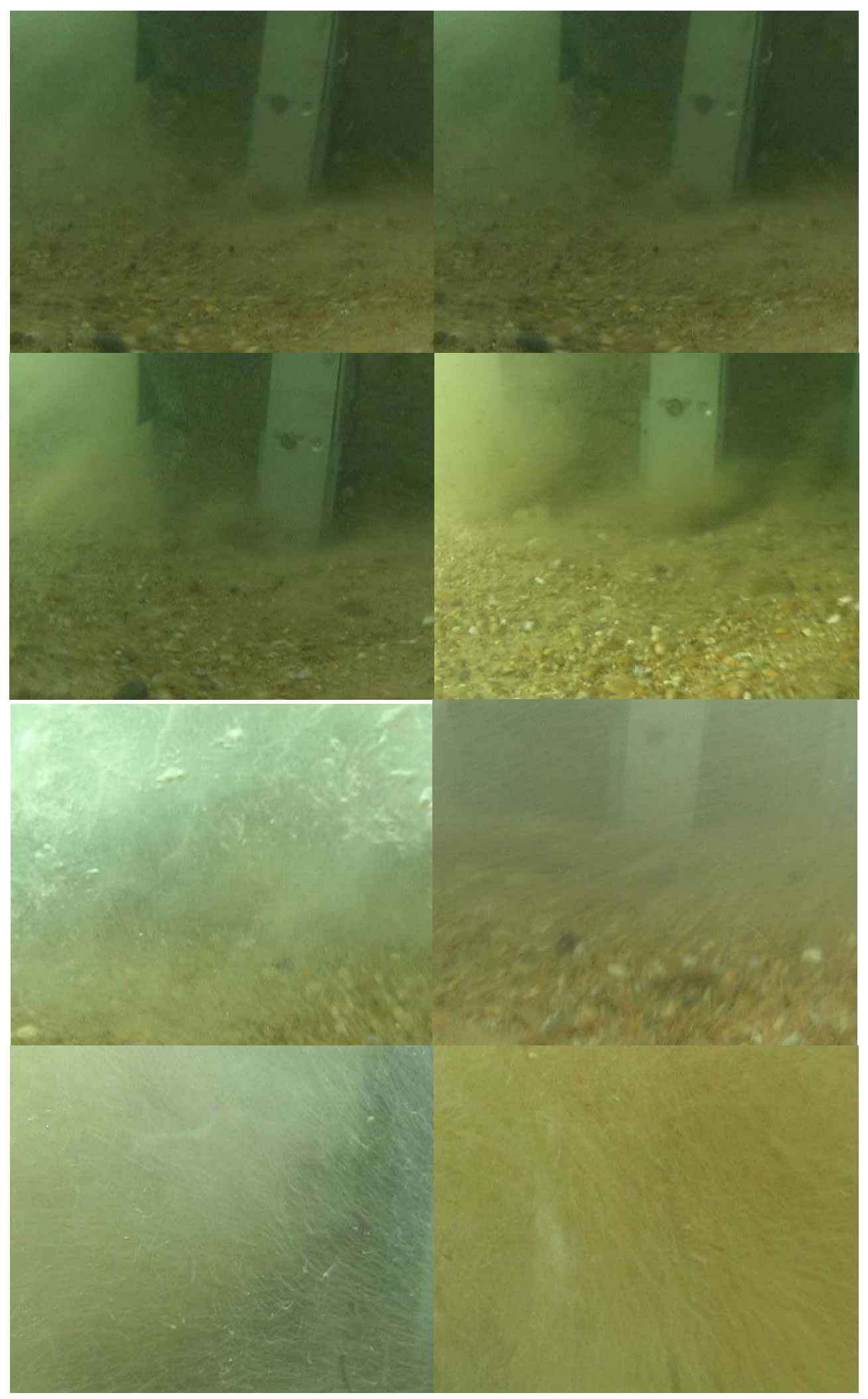

Fig. 3. Video frames showing soil response (corner configuration) that correspond to $t=2.12,2.20,2.28$, 2.60, 3.80, 9.24, 10.80 and 11.12 in Fig. 4 (from left to right and top to bottom). 
a.

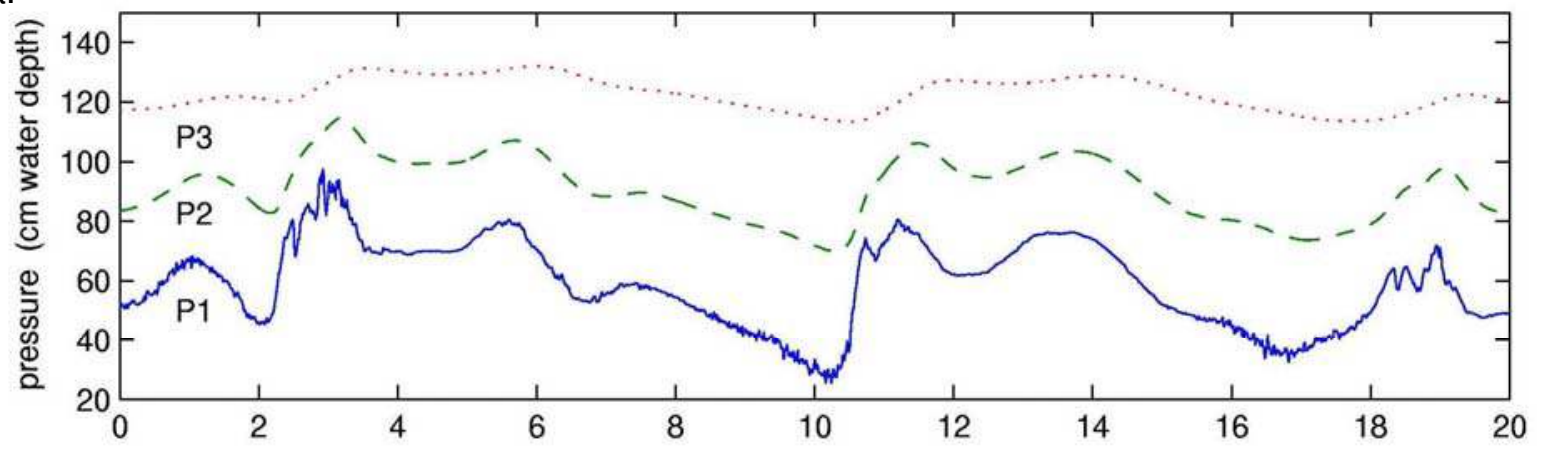

b.

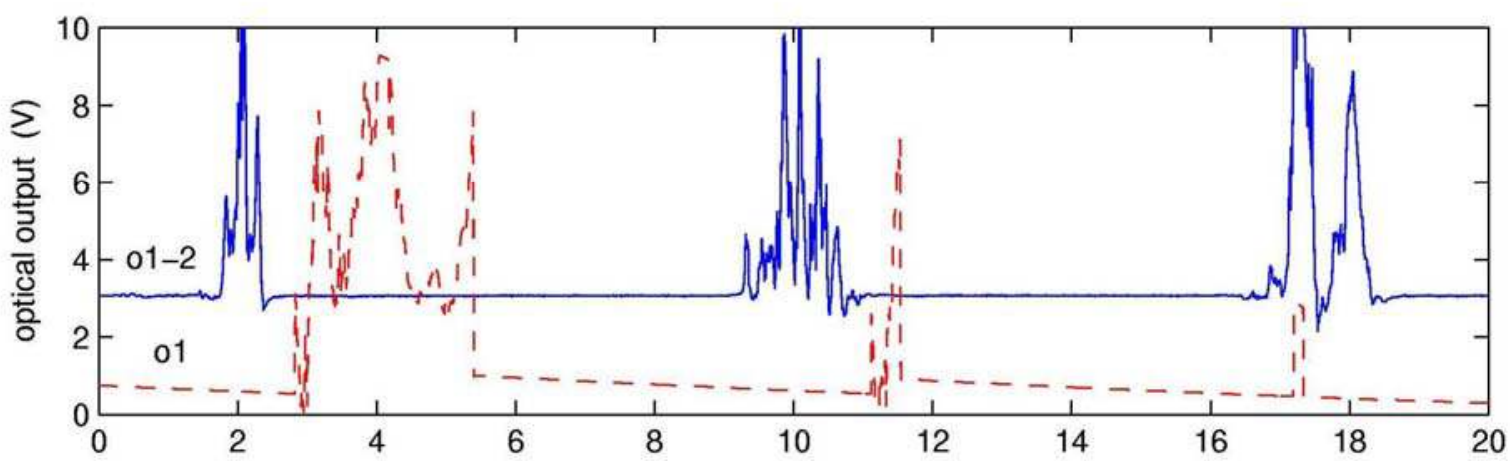

C.
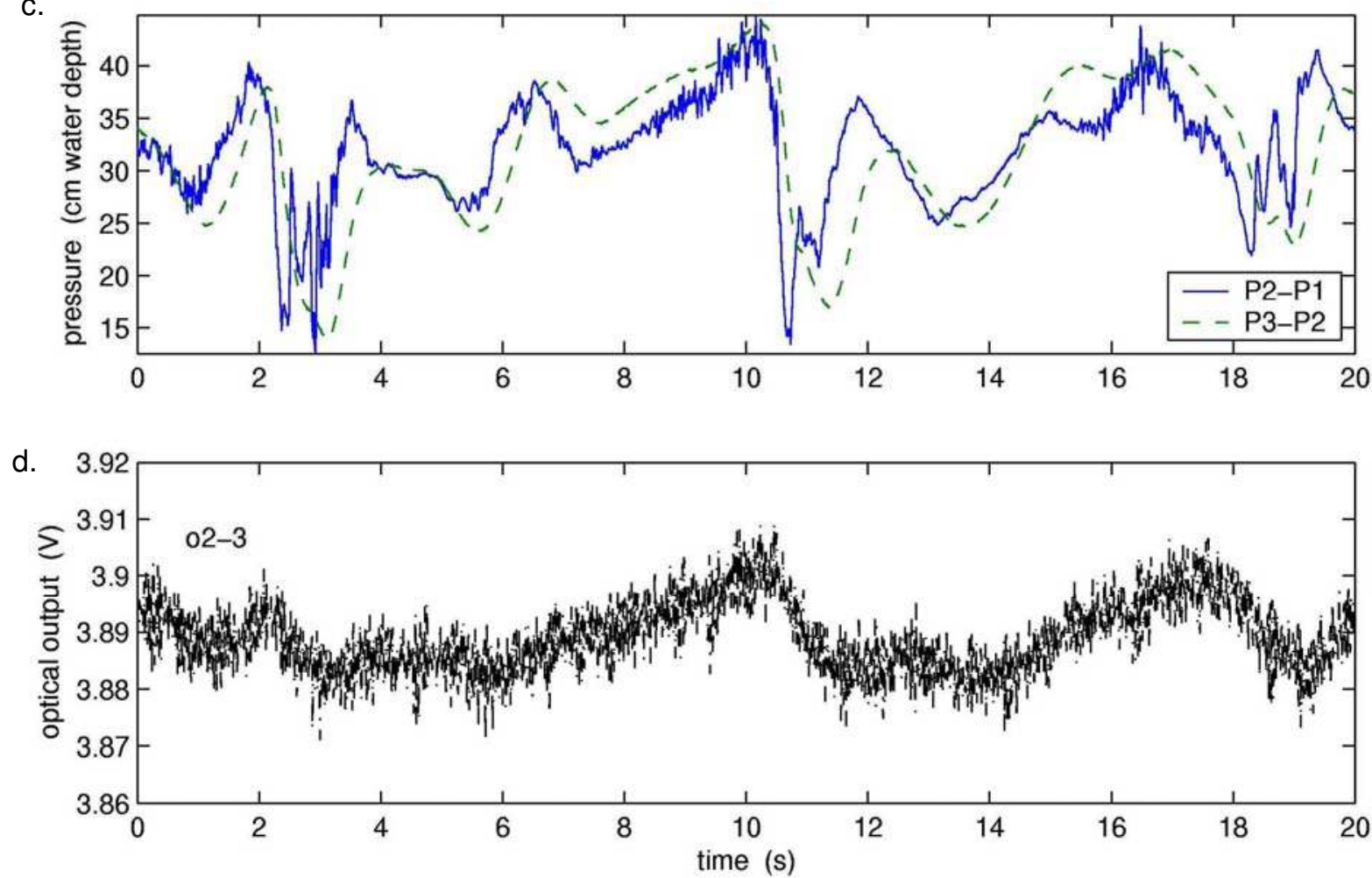

Fig. 4. Time series of the three upper pressure sensors (a); two upper optical sensors (b); two upper pressure differences (c) and the forth upper optical sensor located between P2 and P3 (d). 


\section{Mean sand response over a $10 \mathrm{mn}$ period}

Power density spectra have been computed over $10 \mathrm{mn}$ time series and are plotted in Fig. 5. We first consider the wave energy as determined from pressure variations (top panels). We note the peak wave frequency around $0.1 \mathrm{~Hz}$ and also the harmonics. In the corner configuration (top-right panel) we observe low frequency waves due to the complex refraction and reflection in between the bunkers. Once inside the soil the energy clearly decreases with depth. From these pressure measurements we may infer that the soil/water interface is located between P2 and P3.

We now consider the response of the optical sensors (bottom panels). The energy level indicates the activity at the sensor's depth. In the corner configuration, sensors in the water column record large fluctuations. The high level of energy indicates that sediment is put into suspension with almost every wave. We note that almost all optical sensors present a peak of energy at the wave frequency (around $0.1 \mathrm{~Hz}$ ). This shows that, even deep into the soil, pressure variations are recorded at the wave time scale. The energy level varies with depth, which may be linked to the gas content. We expect larger sand grain motions if air bubbles are located close the sensor. Two sensors require special attention: o2-3 (left) and o3 (right). They show a relatively high energy level at low frequencies (below $0.1 \mathrm{~Hz}$ ). This is probably due to the fact that these sensors are the closest to the soil/water interface and thus experience bed level variations over the $10 \mathrm{mn}$ period considered.
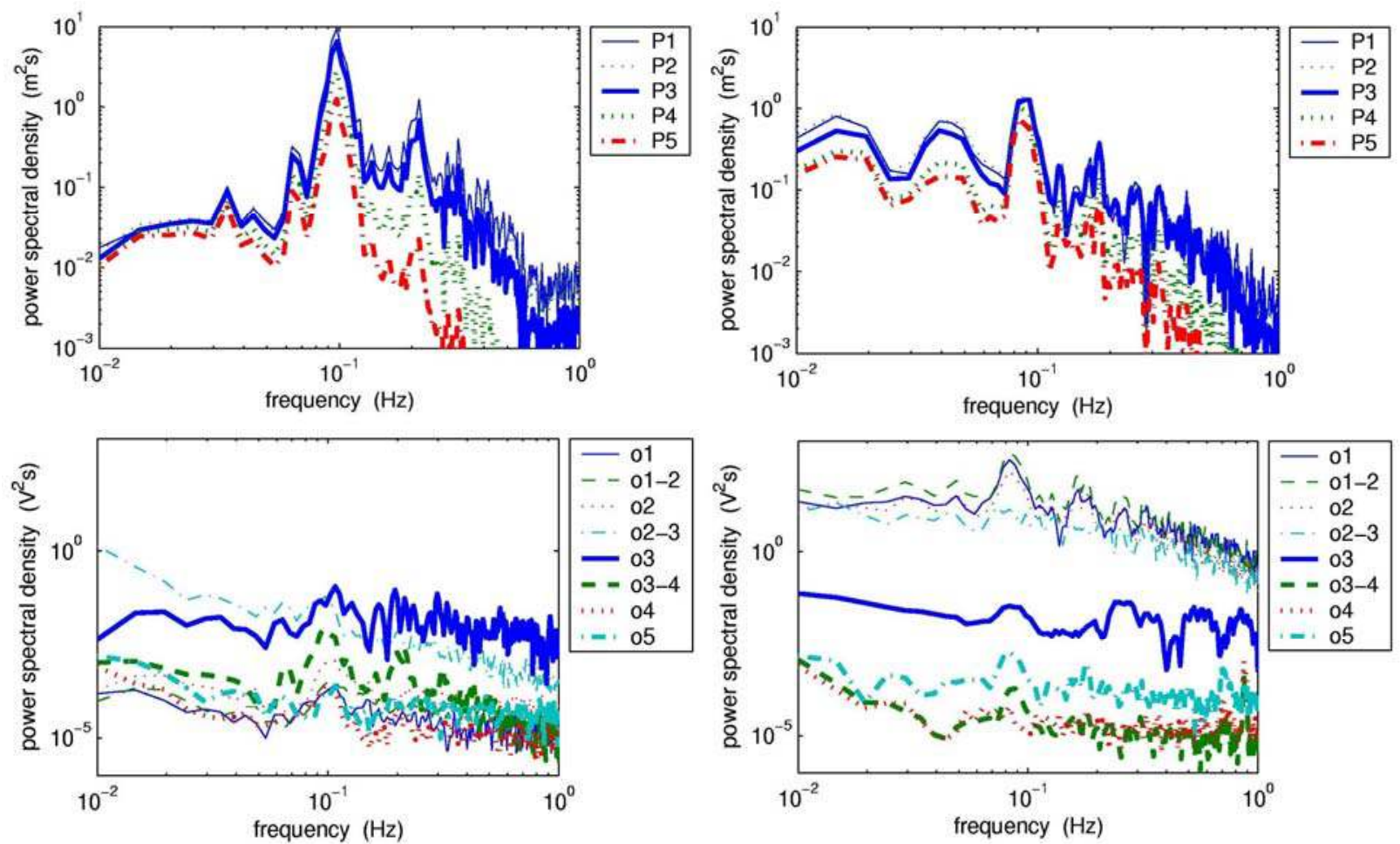

Fig. 5. Power density spectra of $10 \mathrm{mn}$ sequences of pressure (top panels) and optical (bottom panels) measurements for the two configurations: bunker's face (left panels: Sept. 25 15:42-15:52) and bunker's corner (right panels: Oct. 2 8:48-8:58). 


\section{Optical response at the time scale of the tide: water depth evolution}

In Fig. 6 we show the evolution of the optical outputs over a tide for the two different configurations. The mean and maximum water levels inferred from the pressure sensors are also shown in the top panels of Fig. 6. A threshold value for the optical output has been determined from calibration. We have also shown that large fluctuations indicate suspension in the water column or large changes in the bed properties (from the video, see Figs 3 and 4). We may thus estimate a threshold on the fluctuations of the response and plot Fig. 7. We note that the optical estimation of the bed level agrees with the pole measurement in the front configuration. In the corner configuration (panel on the right of Fig. 7), the agreement is rather poor. This is mainly due to local scour at the pole foot induced by the large flow velocities observed.

We now consider the bunker's front configuration in the left panels on Fig. 6. Clearly, waves are breaking against the bunker and significant sediment activity is noticed at the beginning of the tide. This induces an erosion at the structure's toe of about $27 \mathrm{~cm}$ as measured with the pole: $\mathrm{o} 2$, which was in the soil at the preceding low tide, is in the water column at 15:00 (output below the threshold value). Apparently, the soil/water interface is close to $02-3$ since its output varies significantly between 15:10 and 15:30. At high tide (between 16:00 and 18:00), the waves break over the bunker and the soil does not change much. When the water level is lower (18:30-19:00), the waves are breaking against the bunker once more: erosion is measured and even 03 output level is changing. At the end of the tide (after 19:00), accretion is observed.
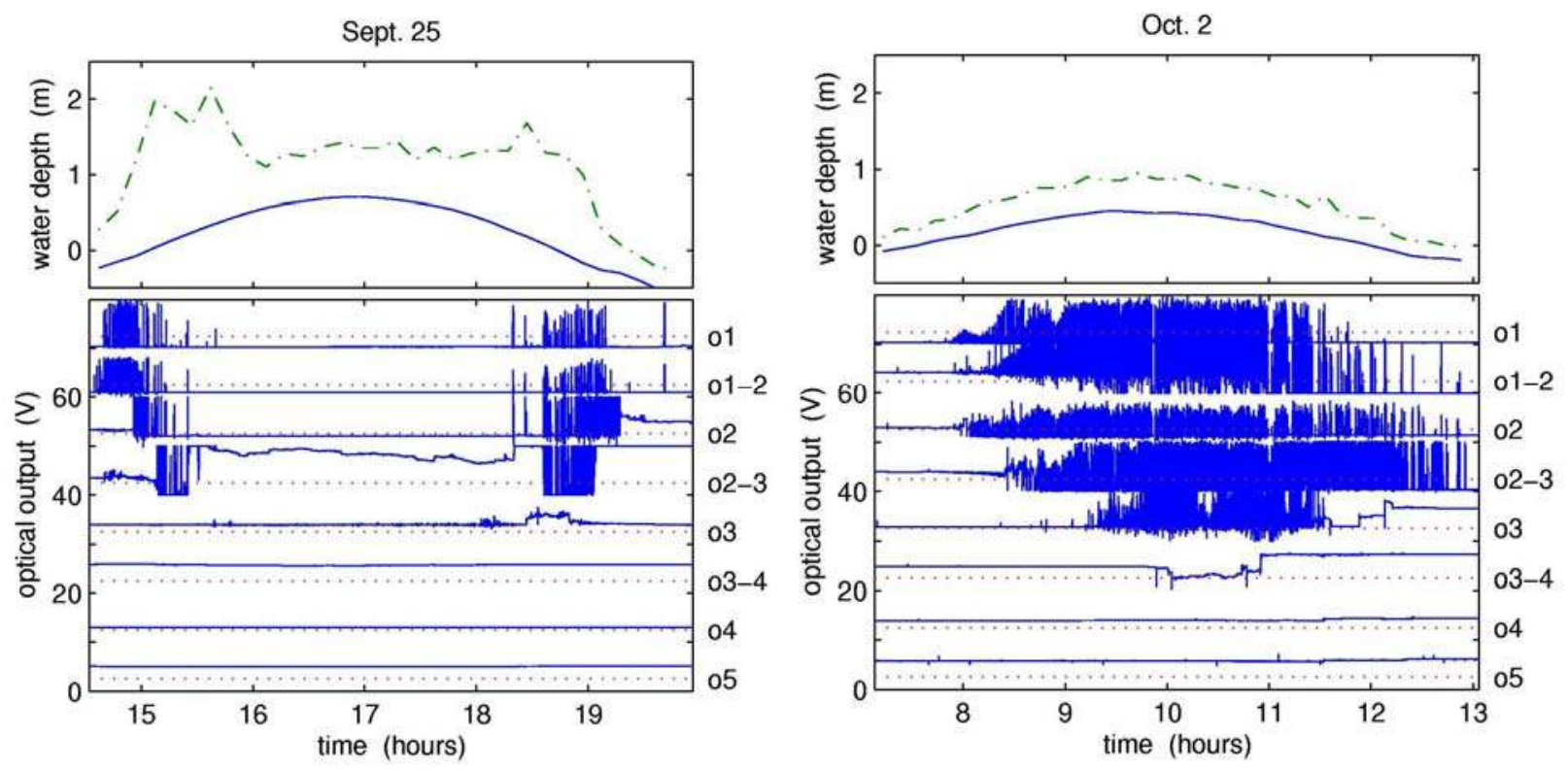

Fig. 6. Optical response over a tide (bottom panels) for the two configurations: bunker's face (left) and bunker's corner (right). There is an offset of multiples of $10 \mathrm{~V}$ for clarity. The threshold value for each sensor is plotted in a dotted line. The mean water level (solid line) and the maximum water level (dashed line) are shown in the top panels. 

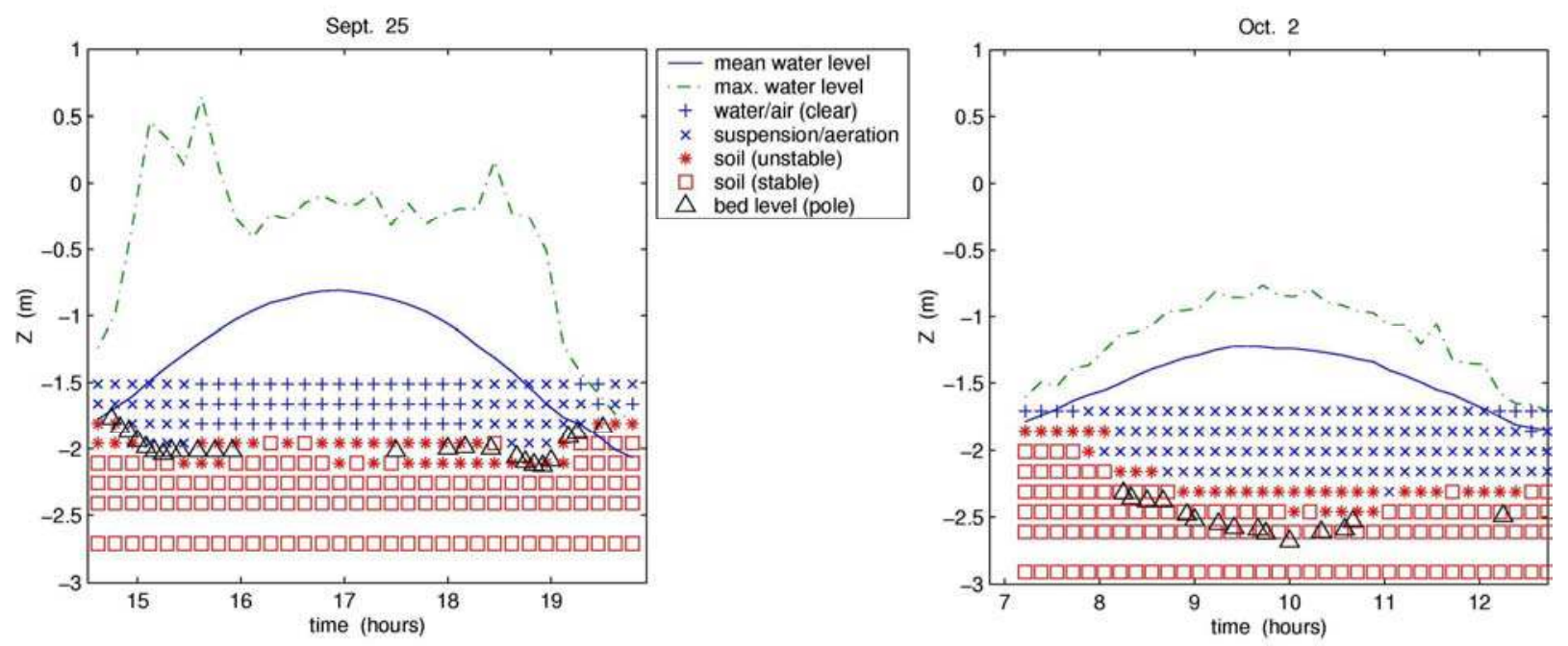

Fig. 7. Comparison of bed level and sediment stability estimations from optical responses with graduated pole measurements over one tide in the two configurations: bunker's face (left) and bunker's corner

(right).

In the other configuration (panels on the right of Fig. 6) we observe the same general feature, erosion at the beginning of the tide and accretion at the end. Both processes are now stronger, more than 60 $\mathrm{cm}$ of erosion and a relatively weaker accretion of about $20 \mathrm{~cm}$ are verified. Suspension is observed all tide long, although the wave energy is a lot weaker compared to the other configuration. Here, in the corner of the bunker, shear induced by the strong longitudinal velocities (as observed in the video, see Fig. 3) is the key sediment transport mechanism.

\section{Particular events}

Figure 8 shows a 20 s time series with interesting features to understand the bed response to breaking waves. A wave is breaking on the structure at $\mathrm{t}=114 \mathrm{~s}$. Optical variations at each depth are recorded in phase with such shock wave. Pressure difference P3-P2 is rapidly increasing to reach a value of about $50 \mathrm{~cm}$ water depth (at $\mathrm{t}=116,119,126$ or 128.5); $\mathrm{o} 3$ and also $\mathrm{o} 2-3$ response is clearly visible. The pressure difference is close to the effective weight of the soil between the two pressure sensors (see Mory et al., 2005). This probably breaks the soil static equilibrium condition locally and thus induces sand mobility.

Two other time series are shown in Figs 9 and 10. The threshold value of pressure difference that would break the soil static equilibrium is plotted as a dotted line in the middle panels. We note that P3-P2 may slightly overshoot this value and a response of $02-3$ is simultaneously recorded. This confirms the occurrence of momentary liquefaction. In the front configuration, this happens at the back of the wave as the water level drops (Fig. 9) while, for the corner configuration, it appears later in the wave trough (Fig. 10). In the latter case, the backwash flow shear leads to large pressure differences that induce sediment mobility and probably enhance the sheet flow. 

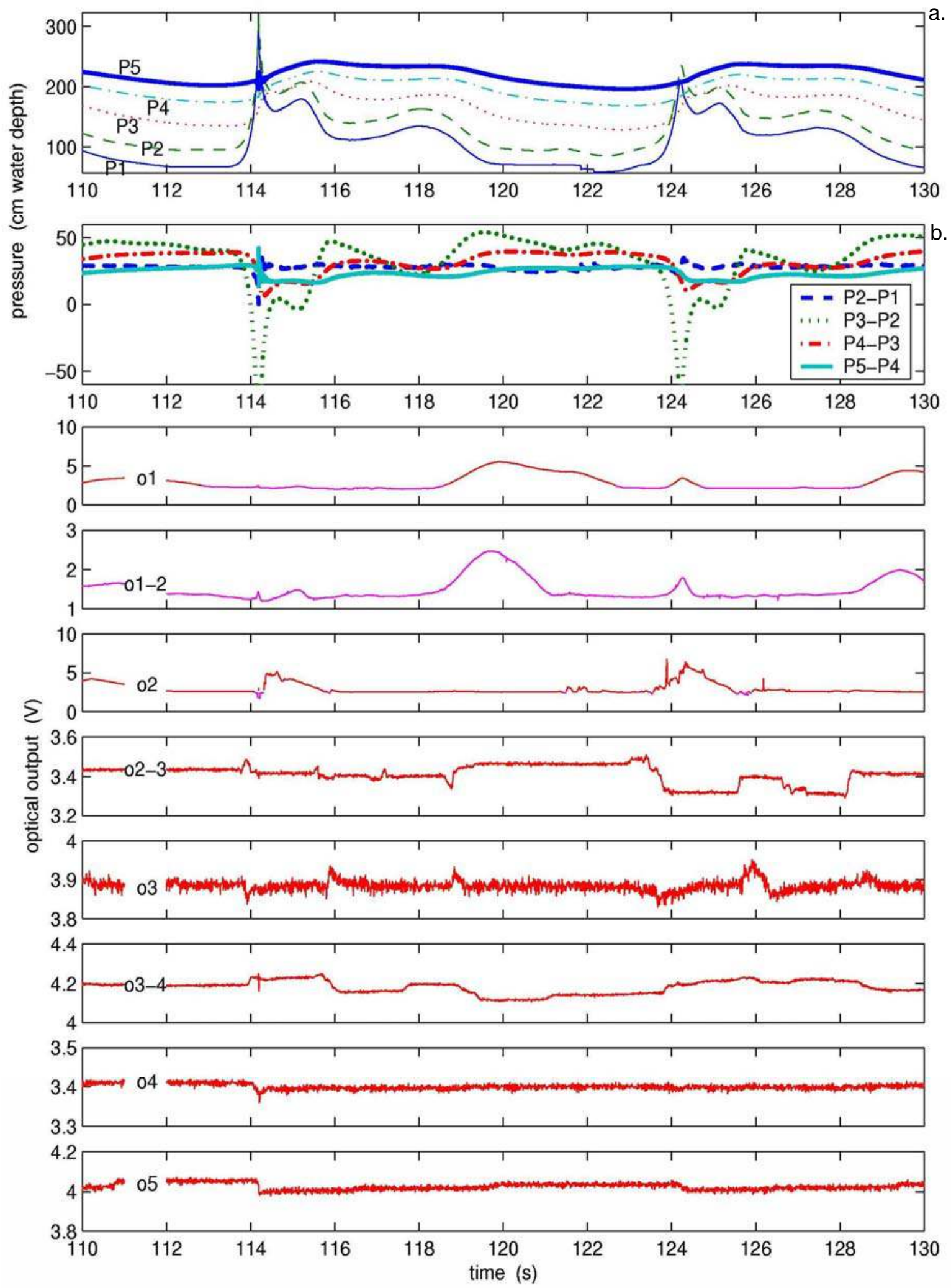

Fig. 8. Time series of pressure (a); pressure differences (b) and the optical outputs (8 bottom panels), front configuration, Sept. 27 16:58:54. The bed level is close to 02 and P2; 05 and P5 are about $90 \mathrm{~cm}$ deep. 


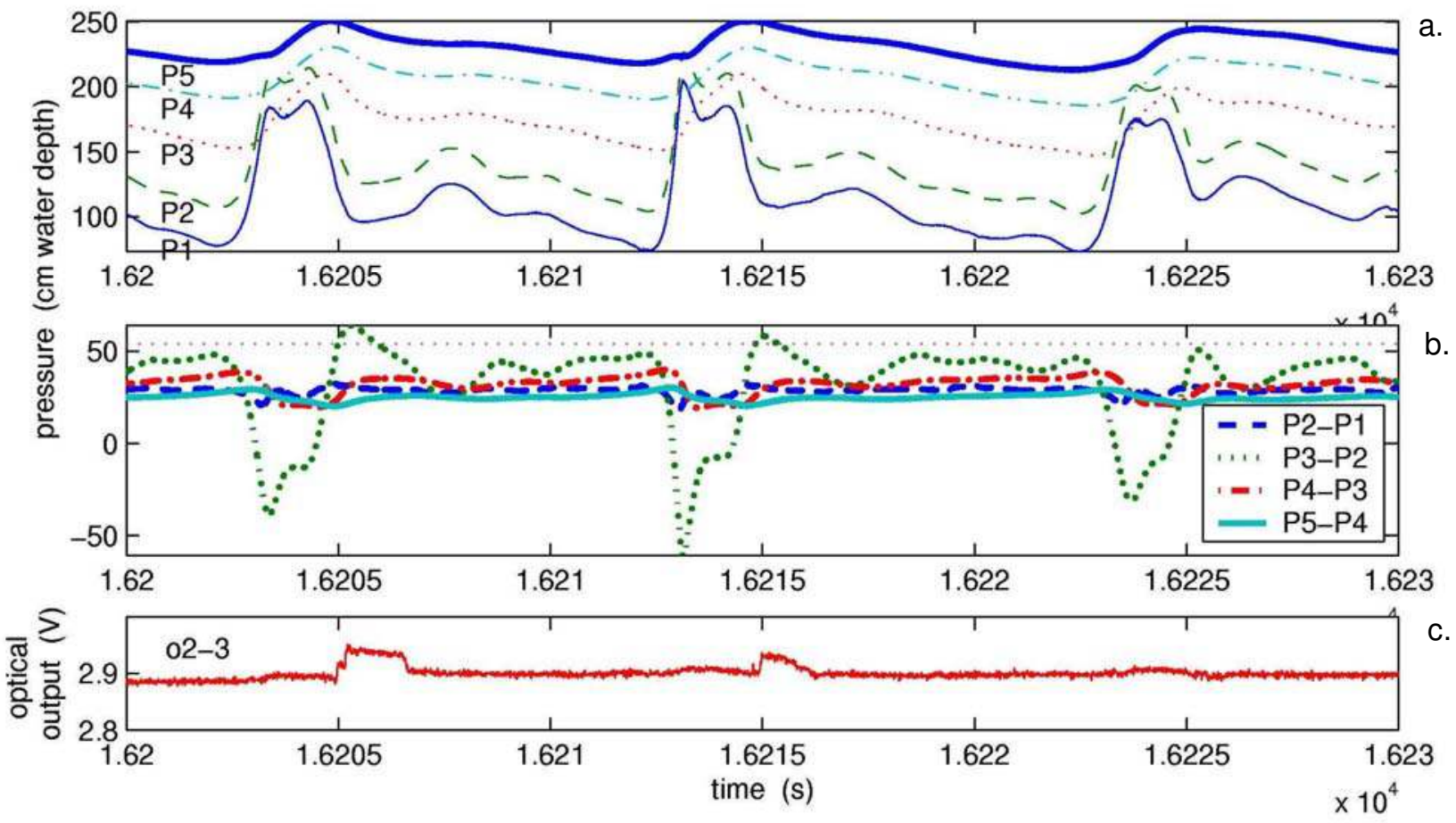

Fig. 9. Time series of pressure (a); pressure differences (b) and optical output $02-3$ (c), front configuration, Sept. 28 7:18:00.

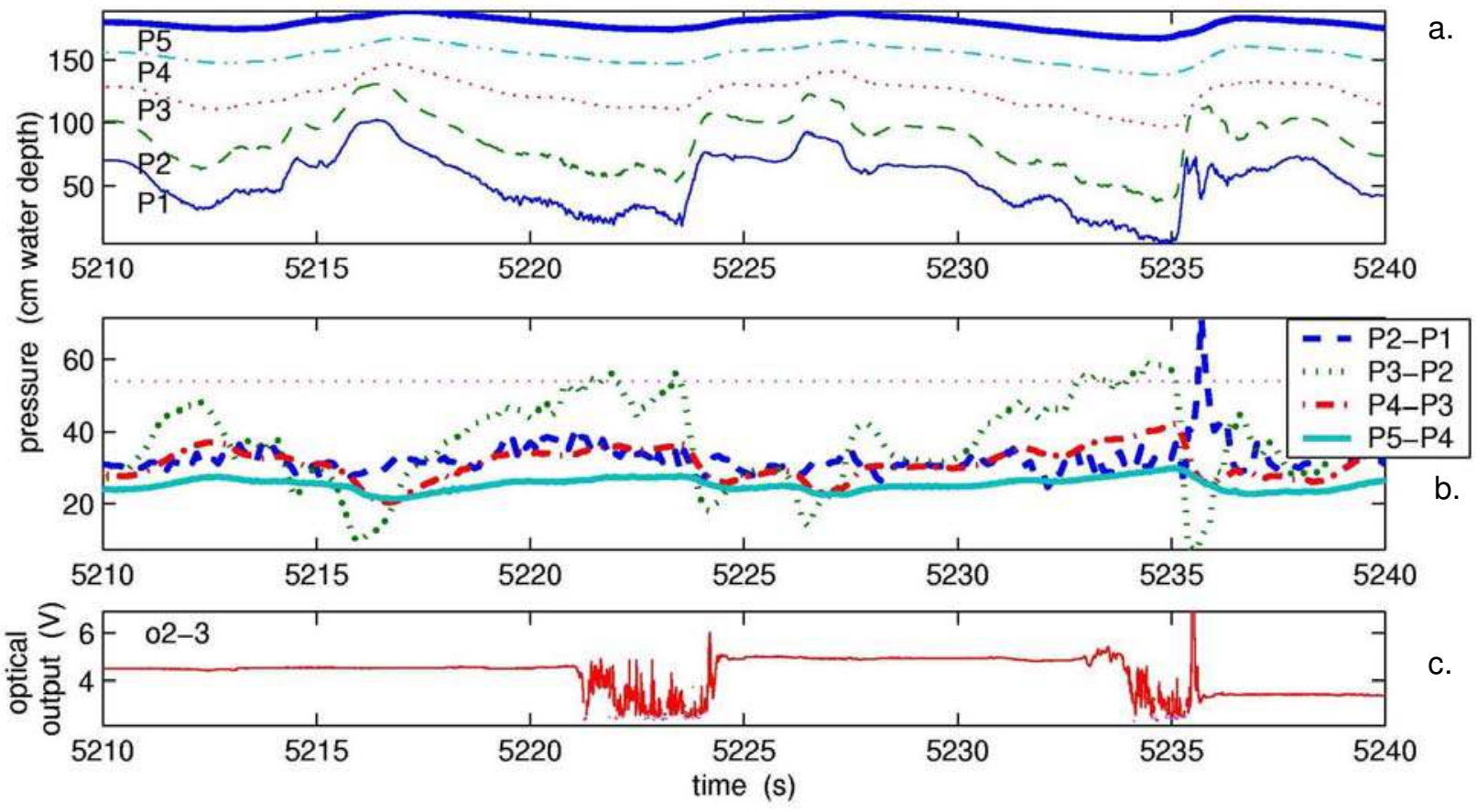

Fig. 10. Time series of pressure (a); pressure differences (b) and optical output o2-3 (c), corner configuration, Oct. 1 20:41:48. 


\section{CONCLUSIONS}

The soil response to breaking waves on a coastal structure was monitored for the first time with an optical system. We have shown its relevance for estimating soil stability. The designed optical system enables to estimate the position of the bed level at the toe of a coastal structure exposed to breaking waves. The configuration chosen has an uncertainty of the order of the spacing of the sensors $(15 \mathrm{~cm})$. Moreover, we have shown that the system determines the sediment activity in the water column. Strong fluctuations indicate that suspension is passing in front of the sensor. A more precise calibration of the system for determining the suspended sediment concentration will be subject of future work. In addition, sand grain mobility inside the soil has been determined. Due to large amounts of gas content (Sandven and Long, 2005), pressure variations modify the trapped air bubbles size and therefore the sand grain arrangement at great depths.

A shock wave, due to a large wave breaking exactly on the structure, is measured at all instrumented depths (maximum depth: $1 \mathrm{~m}$ ). When pressure differences break the soil static equilibrium, liquefaction occurs and soil mobility is measured by the optical system. Even if not new in its conception, the designed optical system is proven valuable for engineers and scientists for determining soil and sediment activity at coastal structures.

In the front configuration, pressure differences inside the soil are mainly due to rapid changes of water level due to breaking. In the corner configuration, pressure differences are due to the shear at the bed level. In both cases, these pressure differences may overcome the effective weight of the soil and break its static equilibrium.

\section{ACKNOWLEDGEMENTS}

This study was partially funded by the European Commission Research Directorate, FP5, specific program "Energy, Environment and Sustainable Development," Contract No EVK3-CT-2000-00038, Liquefaction Around Marine Structures LIMAS.

\section{REFERENCES}

Bonjean, D., Foray, P., Piedra-Cueva, I., Michallet, H., Breul, P., Haddani, Y., Mory, M. and Abadie, S. (2004). "Monitoring of the foundations of a coastal structure submitted to breaking waves: occurrence of momentary liquefaction", Proceedings XIV th ISOPE Conference, Toulon, France, vol. II, 585-592.

Babu, M. R., Sundar, V. and Rao, S. N. (2003). "Measurement of scour in cohesive soils around a vertical pile-simplified instrumentation and regression analysis", IEEE J. Oceanic Eng., 28(1), 106-116.

Cassen, M., Abadie, S., Arnaud, G. and Morichon, D. (2004), "Resistive measurement of seabed local evolution and in depth sediment response to the wave action", Proceedings $29^{\text {th }}$ ICCE Conference, Lisbon, Portugal, 13pp.

Lee, H.J., Jo, H.R., Chu, Y.S. and Bahk, K.S. (2004). "Sediment transport on macrotidal flats in Garolim Bay, west coast of Korea: significance of wind waves and asymmetry of tidal currents", Cont. Shelf Res., 24(7-8), 821-832.

Conley, D.C. and Beach, R.A. (2003). "Cross-shore sediment transport partitioning in the nearshore during a storm event”, J. Geophys. Res., 108(C3), 3065, doi:10.1029/2001JC001230.

Mory, M., Michallet, H., Bonjean, D., Piedra-Cueva, I., Barnoud, J.-M., Foray, P., Abadie, S. and 
Breul, P. (2005). "Momentary liquefaction caused by waves around a coastal structure", ASCE J. Waterway Port Coastal Ocean Eng., accepted for publication.

Piedra-Cueva, I., Michallet, H. and Mory, M. (2005). "Wavelet analysis of pressure measurements near a coastal structure", Proceedings $5^{\text {th }}$ Int. Symp. on Ocean Wave Measurement and Analysis (WAVES 2005), Madrid, Spain, $3^{\text {rd }}-7^{\text {th }}$ July 2005, 11 pp.

Sandven, R. and Long, M., (2005). "Development of Sampler for measurement of gas content", submitted for publication in the J. Waterways, Port, Coastal and Ocean Engineering. 